\title{
Polymerization of Sickle Cell Hemoglobin at Arterial Oxygen Saturation Impairs Erythrocyte Deformability
}

\author{
M. A. Green, C. T. Noguchi, ${ }^{\star}$ A. J. Keidan, S. S. Marwah, and J. Stuart \\ Department of Haematology, Medical School, University of Birmingham, Birmingham B15 2TJ, United Kingdom; \\ and *Laboratory of Chemical Biology, National Institute of Diabetes, and Digestive and Kidney Diseases, \\ National Institutes of Health, Bethesda, Maryland 20892
}

\begin{abstract}
We have examined the filterability of sickle erythrocytes, using an initial-flow-rate method, to determine whether sufficient hemoglobin $\mathbf{S}$ polymer forms at arterial oxygen saturation to adversely affect erythrocyte deformability. The amount of intracellular polymer was calculated as a function of oxygen saturation to estimate the polymerization tendency for each of eight patients with sickle cell anemia (SCA). Progressive reduction of oxygen tension within the arterial range caused a sudden loss of filterability of SCA erythrocytes through 5- $\mu \mathrm{m}$ diam pores at a critical $\mathrm{PO}_{2}$ between 110 and $190 \mathrm{mmHg}$. This loss of filterability occurred at a higher $\mathrm{PO}_{2}$ than did morphological sickling, and the critical $\mathrm{PO}_{2}$ correlated significantly ( $r$ $=0.844-0.881, P<0.01)$ with the polymerization tendency for each patient. Study of density-gradient fractionated cells from four SCA patients indicated that the critical $\mathrm{PO}_{2}$ of dense cells was reached when only a small amount of polymer had formed, indicating the influence of this subpopulation on the results obtained for unfractionated cells. Impairment of erythrocyte filterability at high oxygen saturation $(>90 \%)$ suggests that small changes in oxygen saturation within the arterial circulation cause rheological impairment of sickle cells.
\end{abstract}

\section{Introduction}

Polymerization of hemoglobin $\mathbf{S}$ within the erythrocytes of patients with homozygous sickle cell anemia (SCA) ${ }^{1}$ is the primary factor in loss of erythrocyte deformability and morphological sickling $(1,2)$. Additional factors that contribute to the loss of deformability include erythrocyte dehydration, which causes an increase in mean cell hemoglobin concentration (MCHC) and therefore in cytoplasmic viscosity $(3,4)$, and membrane damage resulting from repeated cycles of sickling (5). The main determinant of polymer formation and hence abnormal rheology in sickle erythrocytes is oxygen saturation $(6,7)$. It was formerly considered that substantial deoxygena-

Address reprint requests to Professor J. Stuart, Department of Haematology, Medical School, University of Birmingham, Birmingham B15 2TJ, United Kingdom.

Received for publication 29 October 1986 and in revised form 23 October 1987.

1. Abbreviations used in this paper: HBS, Hepes-buffered saline; IF, index of filtration; MCHC, mean cell hemoglobin concentration; PCV, packed cell volume; SCA, sickle cell anemia.

J. Clin. Invest.

(c) The American Society for Clinical Investigation, Inc.

$0021-9738 / 88 / 06 / 1669 / 06 \$ 2.00$

Volume 81, June 1988, 1669-1674 tion was required to form polymer and compromise the rheology of sickle cells, but, using ${ }^{13} \mathrm{C}$-nuclear magnetic resonance, intracellular polymer has been detected at very high oxygen saturation levels (8). It is unknown, however, whether sufficient polymer forms at an oxygen saturation equivalent to the arterial side of the microcirculation to adversely affect sickle cell deformability.

As oxygen saturation decreases, the tendency of hemoglobin $\mathrm{S}$ to polymerize increases and the deformability of sickle erythrocytes is reduced. Polymerization in sickle erythrocytes is very sensitive to intraerythrocytic hemoglobin concentration (9) and composition. Based on studies of hemoglobin $\mathbf{S}$ polymerization in solution and ${ }^{13} \mathrm{C}$-nuclear magnetic resonance measurements of polymer formation within intact sickle erythrocytes, the extent of polymerization can be calculated for any hemoglobin composition and concentration (10). Such calculations have been used to demonstrate that polymer formation could account for at least $80 \%$ of the variation in hemolytic rate and clinical severity among 12 different sickle syndromes (11). Rheological methods used previously for the study of sickle cells have included viscosity measurements on whole blood or washed erythrocytes (6), measurement of erythrocyte elongation by laser diffractometry (12), micropipette determination of membrane viscoelasticity (13), and the gravity filtration of erythrocytes through $5-\mu \mathrm{m}$-diam pores (14). The last technique is sensitive to factors that alter cytoplasmic viscosity, including an increase in MCHC (15), and should therefore be sensitive to the rheological effects of both hemoglobin S polymerization and cytoplasmic dehydration in sickle erythrocytes.

To investigate the relationship between the rheology of sickle cells and hemoglobin $\mathrm{S}$ polymerization at high oxygen saturation, we have studied the filterability of erythrocytes from eight patients with homozygous SCA and have determined the minimum degree of oxygen desaturation required to compromise erythrocyte deformability. We correlated this degree of oxygen desaturation with the polymerization tendency of these cells.

\section{Methods}

Venous blood samples anticoagulated with dry lithium heparin from eight patients with homozygous SCA and tested within $6 \mathrm{~h}$ were prefiltered through cotton wool (Imugard IG 500; Terumo Corp., Tokyo, Japan) to reduce contaminating leukocytes to $<0.025 \times 10^{9} / 1(16)$. Twice-washed erythrocytes were resuspended at a packed cell volume (PCV) of $\sim 0.05(5 \%)$ in $20 \mathrm{mmol} /$ liter Hepes-buffered saline (HBS) at pH 7.4 measured at $37^{\circ} \mathrm{C}$ and $290 \mathrm{mmol} /$ liter osmolality. $20 \mathrm{ml}$ of this suspension was deaxygenated by gently bubbling with moist $95 \%$ $\mathrm{N}_{2} / 5 \% \mathrm{CO}_{2}$ at $37^{\circ} \mathrm{C}$ for $1 \mathrm{~h}$, and another $20 \mathrm{ml}$ was kept on a roller mixer at atmospheric oxygen at $37^{\circ} \mathrm{C}$ for $1 \mathrm{~h}$. A 2-ml aliquot of each suspension and $6 \mathrm{ml}$ HBS buffer were then equilibrated with one of 


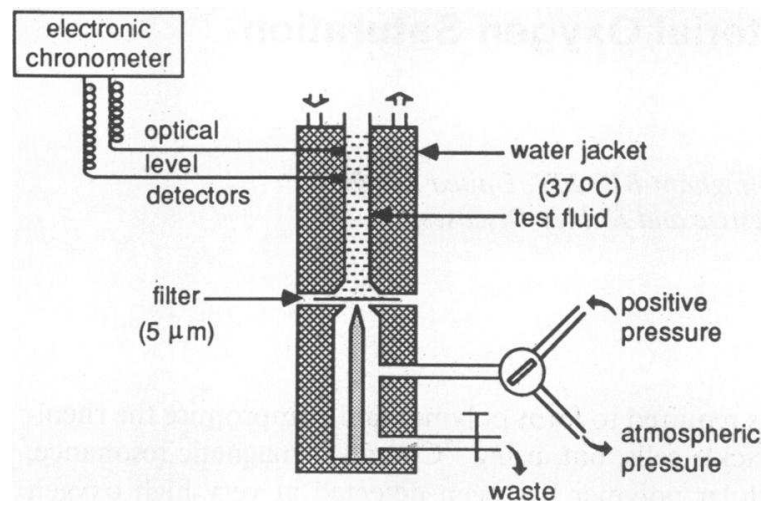

Figure 1. Cross-section of Hemorheometre to show vertical capillary tube (height, $6 \mathrm{~cm}$; internal diameter, $2.5 \mathrm{~mm}$ ) containing erythrocyte suspension held by positive back-pressure above $5-\mu \mathrm{m}$ pore filter membrane. Release of pressure allows flow of test fluid under gravity, and the optical level detectors measure flow rate of the initial $60 \mu \mathrm{l}$.

eight gas mixtures of $95,25,20,17,14,12,10$, and $8 \% \mathrm{O}_{2}$ and balance $\mathrm{N}_{2}$ with $5 \% \mathrm{CO}_{2}$ (gas mixing pump; $\mathrm{H}$. Wösthoff, Bochum, Germany) using miniature tonometers modified from $30-\mathrm{ml}$ Universal plastic containers (Sterilin Ltd., Feltham, Middlesex, England), which were fitted with gas-tight nozzles. The gas mixture was bubbled through the tonometer for $2.5 \mathrm{~min}$ and the contents mixed on a roller mixer at $37^{\circ} \mathrm{C}$ for $1 \mathrm{~h}$. The final $\mathrm{pH}$ of 7.0 was maintained throughout this period.

Erythrocyte filterability was measured at $37^{\circ} \mathrm{C}$ using a Hemorheometre (Mk I; IMH, St. Witz, France) (Fig. 1) as an initial-flow-rate index of filtration (IF) corrected for PCV as described by Hanss (17). Filter membranes of 5- $\mu \mathrm{m}$ pore diameter (batch $54 \mathrm{H} 3 \mathrm{C} 30$; Nuclepore Corp., Pleasanton, CA) were cleaned by ultrasonication and reused (18). HBS equilibrated with the appropriate gas mixture was used to determine the buffer flow time through the membrane $\left(t_{b}\right)$. The Hemorheometre capillary tube and filter chamber were then flushed with $10 \mathrm{ml}$ of gas from a tonometer containing gas at the appropriate percentage oxygen before measurement of the flow time of the erythrocyte suspension through the membrane $\left(t_{\mathrm{e}}\right)$. The position of the two optical detectors (Fig. 1) ensures that only the initial-flow-rate $(60 \mu \mathrm{l})$ is measured, thereby reducing the influence of pore clogging by erythrocyte subpopulations. The IF was calculated as: $\left(t_{\mathrm{e}}-t_{\mathrm{b}}\right) / t_{\mathrm{b}} \times 100 / \mathrm{PCV}(\%)$. $\mathrm{PO}_{2}$ was measured using an acid base analyzer with attached oxygen electrode (PHM 71 Mark 2; Radiometer, Copenhagen, Denmark). Erythrocyte indices were determined from the microhematocrit centrifuged PCV $(13,000 \mathrm{~g}$ for $15 \mathrm{~min})$ of oxygenated sickle cells and the Coulter counter (S Plus IV; Coulter Electronics, Luton, England) erythrocyte count and hemoglobin concentration (Table I). Percentage hemoglobin S was measured using a Paragon hemoglobin electrophoresis kit at pH 8.6 (Beckman Instruments Inc., Fullerton, CA) and fetal hemoglobin by alkali denaturation (19). Oxygen saturation curves on erythrocytes in HBS (PCV $\sim 0.35 ; 35 \%$ ) were determined as association curves at $37^{\circ} \mathrm{C}$ using an Aminco oxygen dissociation analyzer (Hem-O-Scan; American Instrument Co., Silver Spring, MD). Erythrocyte morphology was assessed by interference microscopy by fixing one drop of erythrocyte suspension in $1 \mathrm{ml}$ of $0.025 \% \mathrm{vol} / \mathrm{vol}$ glutaraldehyde in HBS equilibrated with the appropriate gas mixture. A total of 200 cells was examined by one operator using interference microscopy and classified according to Bessis (20).

Polymer formation at different oxygen saturations for each sample was calculated using the $\mathrm{MCHC}$ and proportions of S and non-S hemoglobins. The method for determining hemoglobin $S$ polymerization included the effects of protein and water nonideality (10). To calculate polymer formation at nonzero oxygen saturations, the following assumptions were made: the partition of various hemoglobin species (such as hemoglobins S, F, or the S-F hybrid hemoglobin) follows a binomial distribution, the oxygen affinity of all hemoglobin species is similar, and hemoglobin species containing gamma or delta globin chains (hemoglobins $\mathrm{F}$ or $\mathrm{A}_{2}$ or the corresponding hybrid hemoglobins) do not copolymerize with hemoglobin S. These calculations together provide a lower limit for the amount of polymer formed, as most deviations from these assumptions would tend to increase the actual amount of polymer at any oxygen saturations.

A typical plot of predicted polymer fraction, for erythrocytes of average density, is shown as a function of oxygen saturation for one of the patients (C.D.) in Fig. 2. The relevant parameters used in the comparison with erythrocyte filterability are the polymer fraction at $0 \%$ saturation (most precise calculation) and at $70 \%$ oxygen saturation (of greater physiological relevance).

To isolate subpopulations of sickle erythrocytes, washed cells, after filtration through Imugard IG 500 cotton wool, were separated using a modified Percoll-Stractan continuous density gradient (21) that was centrifuged at $30,000 \mathrm{~g}$ for $20-30 \mathrm{~min}$ at $15^{\circ} \mathrm{C}$. Fractions $1,2,3$, and 4 (in increasing order of density) were isolated by sequential aspiration from the top of the gradient. Density marker beads were used to determine the density throughout the gradient. Oxygen saturation curves were measured as before and filtration was performed at $25^{\circ} \mathrm{C}$. Erythrocyte indices of the fractionated samples were determined by the Coulter S Plus IV counter (Coulter Electronics).

Table I. Filtration Measurements and Polymer Formation for Unfractionated SCA Erythrocytes

\begin{tabular}{|c|c|c|c|c|c|c|c|c|}
\hline \multirow[t]{2}{*}{ Patient } & \multirow{2}{*}{$\frac{\mathrm{MCHC}}{g / d l}$} & \multirow{2}{*}{$\begin{array}{c}\mathrm{HbS} \\
\%\end{array}$} & \multirow{2}{*}{$\frac{P_{s 0}^{*}}{m m H g}$} & \multirow{2}{*}{$\begin{array}{c}\begin{array}{c}\mathrm{Critical}_{\mathrm{Po}}{ }^{*} \\
\text { (oxygenated) }\end{array} \\
\mathrm{mmHg}\end{array}$} & \multirow{2}{*}{$\frac{\begin{array}{c}\text { Critical } \mathrm{PO}_{2} \\
\text { (deoxygenated) }\end{array}}{m m \mathrm{Hg}}$} & \multirow{2}{*}{$\frac{\text { Sat }_{\text {orill }}}{\%}$} & \multicolumn{2}{|c|}{ Polymer fraction predicted } \\
\hline & & & & & & & $0 \%$ sat & $70 \%$ sat \\
\hline C.D. & 34.5 & 92.8 & 46 & 165 & 165 & 99 & 0.61 & 0.15 \\
\hline L.S. & 33.2 & 89.6 & 54 & 133 & 127 & 97 & 0.55 & 0.11 \\
\hline N.S. & 34.0 & 85.4 & 46 & 140 & 112 & $97^{\prime}$ & 0.52 & 0.11 \\
\hline J.S. & 33.6 & 76.3 & 46 & 113 & 110 & 93 & 0.41 & 0.08 \\
\hline H.F. & 33.0 & 87.8 & 45 & 136 & 137 & 95 & 0.53 & 0.10 \\
\hline Y.C. & 34.8 & 87.8 & 38 & 165 & 175 & 99 & 0.56 & 0.14 \\
\hline K.S. & 34.5 & 90.0 & 51 & 185 & 190 & 99 & 0.58 & 0.14 \\
\hline A.C. & 33.1 & 94.3 & 49 & 175 & 170 & 99 & 0.60 & 0.12 \\
\hline
\end{tabular}

* Oxygen tension at which hemoglobin was $50 \%$ saturated. ${ }^{\ddagger}$ Critical $\mathrm{PO}_{2}$ determined for cells preincubated with atmospheric oxygen. ${ }^{8} \mathrm{Criti}-$ cal $\mathrm{PO}_{2}$ determined for cells first deoxygenated with $95 \% \mathrm{~N}_{2} / 5 \% \mathrm{CO}_{2}$. "Sat crit $_{\text {is }}$ the percent oxygenated hemoglobin corresponding to the critical $\mathrm{PO}_{2}$ (oxygenated values equal deoxygenated values). "Sat crit oxygenated value; deoxygenated value is $95 \%$. 


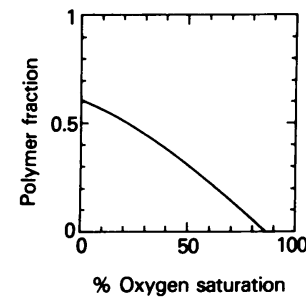

Figure 2. Calculated $\mathrm{Hb} \mathrm{S}$ polymer fraction as a function of oxygen saturation. The $\mathrm{MCHC}$ and proportions of $\mathrm{S}$ and non-S hemoglobin for patient C.D. are used.

\section{Results}

As sickle erythrocytes were deoxygenated, a sudden loss of filterability (as shown by an increase in IF) was observed at a critical $\mathrm{PO}_{2}$ (Fig. 3) in the region 110 to $185 \mathrm{mmHg}$ (Table I). Critical $\mathrm{PO}_{2}$ was determined by extrapolating the vertical part of the deoxygenation curve toward an IF of zero and the horizontal part of the curve toward a $\mathrm{PO}_{2}$ of zero; the point of intersection of the two lines was taken as the critical $\mathrm{PO}_{2}$. When 10 replicate measurements of the critical $\mathrm{PO}_{2}$ were made on blood from one SCA patient, the coefficient of variation was $4.0 \%$. This included the errors in measuring IF and interpreting the 10 deoxygenation curves. $\mathrm{A}$ critical $\mathrm{PO}_{2}$, characterizing an abrupt change in filterability behavior, was also observed when sickle erythrocytes were first deoxygenated and then equilibrated with the gas mixture (Fig. 3). The value for the critical $\mathrm{PO}_{2}$ obtained during the deoxygenation cycle was similar to that obtained during the reoxygenation cycle (Table I). The critical $\mathrm{PO}_{2}$ was equivalent to an oxygen saturation $>90 \%$, as measured by the Hem-O-Scan, for the eight patients (Table I). Filterability continued to decrease (the IF continued to increase) with decreasing $\mathrm{PO}_{2}$. In four samples with very high IF values, there was a secondary fall in IF on further deoxygenation $(<100 \mathrm{mmHg}$ ) after a peak had been reached (Fig. 3), presumably due to further increase in polymer formation and loss of filterability of individual sickle erythrocytes, allowing buffer to flow through partially blocked filter pores and triggering the optical sensors to give a falsely short flow time (22). The $8 \% \quad \mathrm{O}_{2}$ gas mixture gave $\mathrm{PO}_{2}$ values ranging from 73 to $90 \mathrm{mmHg}$. There was no significant increase in percentage of sickled cells, or other morphological change, in any erythrocyte samples corresponding to the ascending arm

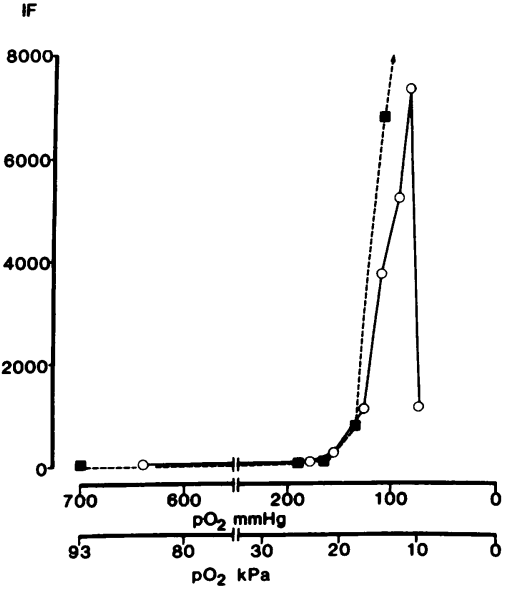

Figure 3. Effect of increasing deoxygenation (fall in $\mathrm{PO}_{2}$ ) on the filterability (IF) of SCA erythrocytes from patient C.D. showing rapid increase in IF at a critical $\mathrm{PO}_{2}$. (O, sample preincubated with atmospheric oxygen for 1 $\mathrm{h}$ at $37^{\circ} \mathrm{C} ; \mathrm{m}$, sample predeoxygenated for $1 \mathrm{~h}$ at $37^{\circ} \mathrm{C} ; 1 \mathrm{~K} P_{\mathrm{a}}=7.5$ mmHg.)

of each IF graph (Fig. 3). When a secondary fall in IF did occur, most of the cells had become spiculated in appearance. Throughout the $\mathrm{PO}_{2}$ range examined and for all samples, erythrocytes that had first been deoxygenated for $1 \mathrm{~h}$ at $37^{\circ} \mathrm{C}$ showed a higher peak IF than erythrocytes that were preequilibrated with atmospheric oxygen for $1 \mathrm{~h}$ at $37^{\circ} \mathrm{C}$ (Fig. 3).

The mean polymer fraction in sickle erythrocytes as a function of oxygen saturation was determined for each patient from the MCHC and the proportions of hemoglobin $S$ and non-S hemoglobins using computer estimates (Table I). The polymer fraction present at oxygen saturations of 0 and $70 \%$ were selected as an indicator of polymerization tendency that showed a significant linear relationship ( $r=0.844$ and 0.881 , respectively, $P<0.01$ ) with the critical $\mathrm{PO}_{2}$ at which IF suddenly increased (Fig. 4).

A pilot study was performed to determine whether the loss of filterability was the result of rheological change in all erythrocytes or in a subpopulation of cells that selectively obstructed membrane pores. Sickle erythrocytes from four patients with homozygous SCA were separated using a modified Percoll-Stractan continuous density gradient (21). More than $90 \%$ of the cells were recovered in fractions 2,3 , and 4 , the dense fraction 4 cells constituting $21 \%$ of the total. Erythrocyte filtration was measured as a function of oxygen tension for fractions 2, 3, and 4, and the critical $\mathrm{PO}_{2}$ was determined. We observed (Table II) for each set of data that while fractions 2 and 3 (low and intermediate density) exhibited lower critical $\mathrm{PO}_{2}$ values than that for the unfractionated sample, fraction 4 (high density) exhibited a critical $\mathrm{PO}_{2}$ value higher than the unfractionated sample.

The polymer fraction for each sample was calculated from the MCHC. For the unfractionated samples with a heterogeneous distribution in corpuscular hemoglobin concentration, the calculated polymer fraction corresponding to the critical $\mathrm{PO}_{2}$ was low $(0-0.08)$. These calculations based on mean red cell indices underestimate the amount of polymer at high oxygen saturations when cell heterogeneity is not explicitly considered. For the fractionated subpopulations, which had a more homogeneous corpuscular hemoglobin concentration, polymer fraction at the critical $\mathrm{PO}_{2}$ is a more meaningful number and ranged from 0.05 to 0.26 (Table II). Specifically, the mean values (SD) for the four patients were $0.17(0.06), 0.10$ (0.07), and $0.11(0.06)$ for fractions 2,3 , and 4 , respectively. $r=0.844, p<0.01$
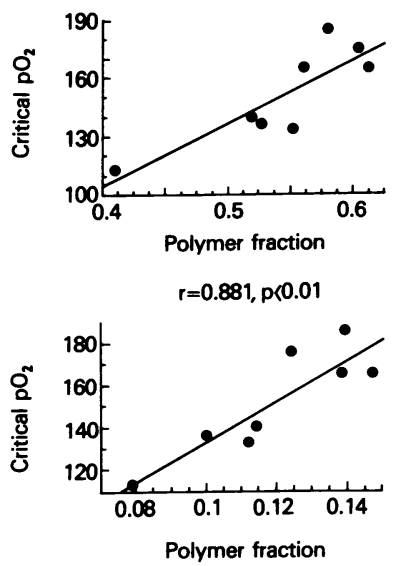

Figure 4. Critical $\mathrm{PO}_{2}(\mathrm{mmHg})$ vs. polymerization tendency. The critical $\mathrm{PO}_{2}$ at which the abrupt change in the index of filtration occurs is plotted against the polymer fraction calculated for $0 \%$ oxygen saturation (top) and $70 \%$ oxygen saturation (bottom). The critical $\mathrm{PO}_{2}$ (oxygenated) (see Table I) is used. Note that the polymer fraction is for the same oxygen saturation, not oxygen tension. 
Table II. Filtration Measurements and Polymer Formation for Density-fractionated SCA Erythrocytes

\begin{tabular}{|c|c|c|c|c|c|c|}
\hline Patient & Fraction & MCHC & $\mathrm{HbF}$ & $\begin{array}{l}\text { Critical } \mathrm{PO}_{2} \\
\text { (oxygenated) }\end{array}$ & $S a t_{\text {cit }}{ }^{*}$ & $\begin{array}{c}\text { Polymer fraction } \\
\text { at critical } \mathrm{PO}_{2}\end{array}$ \\
\hline & & $g / d l$ & $\%$ & $m m H g$ & $\%$ & $\%$ \\
\hline \multirow[t]{4}{*}{ A.C. } & $\mathrm{UF}^{*}$ & 33.9 & 3.6 & 81 & 82 & $-\S$ \\
\hline & 2 & 32.6 & 3.3 & 55 & 55 & 0.18 \\
\hline & 3 & 33.1 & 4.9 & 69 & 65 & 0.12 \\
\hline & 4 & 38.1 & 2.1 & 108 & 77 & 0.11 \\
\hline \multirow[t]{4}{*}{ C.D. } & $\mathrm{UF}^{*}$ & 34.3 & 7.4 & 72 & 78 & - \\
\hline & 2 & 33.6 & 5.8 & 50 & 65 & 0.13 \\
\hline & 3 & 33.5 & 6.9 & 60 & 65 & 0.09 \\
\hline & 4 & 38.8 & 3.4 & 89 & 74 & 0.16 \\
\hline \multirow[t]{4}{*}{ H.F. } & $\mathrm{UF}^{*}$ & 33.2 & 7.6 & 81 & 87 & - \\
\hline & 2 & 32.4 & 6.4 & 55 & 65 & 0.11 \\
\hline & 3 & 30.8 & 11.6 & 58 & 62 & 0.05 \\
\hline & 4 & 35.5 & 6.7 & 97 & 76 & 0.06 \\
\hline \multirow[t]{4}{*}{ C.C. } & $\mathrm{UF}^{*}$ & 35.4 & 4.0 & 74 & 77 & - \\
\hline & 2 & 34.3 & 6.1 & 51 & 57 & 0.26 \\
\hline & 3 & 34.0 & 7.8 & 60 & 65 & 0.13 \\
\hline & 4 & 38.3 & 2.3 & 105 & 79 & 0.10 \\
\hline
\end{tabular}

* UF represents the unfractionated cell population. ${ }^{\ddagger} \mathrm{Sat}_{\text {crit }}$ is the percent oxygenated hemoglobin corresponding to the critical $\mathrm{PO}_{2}$. ${ }^{\S} \mathrm{Calcu}_{-}$ lated polymer fraction from mean indices is an underestimate due to cell heterogeneity and is not included in the table.

\section{Discussion}

Patients with SCA suffer acute episodes of tissue ischemia (painful or vasoocclusive crises) as a consequence of abnormal intravascular erythrocyte rheology. It is uncertain whether the initiating event occurs in the arteriolar, capillary, or venular areas of the microcirculation. Although the potential importance of intracellular hemoglobin S polymer formation in the arterial circulation was realized when polymer was demonstrated at high oxygen saturation (8), the rheological significance of this finding was uncertain. By demonstrating loss of erythrocyte filterability (deformability) at high oxygen saturation, and also a correlation between the critical $\mathrm{PO}_{2}$ and the polymerization tendency, this study underlines the rheological importance of polymer formation in the arterial (including arteriolar) circulation.

Filtration of erythrocytes through pores $5 \mu \mathrm{m}$ in diameter and $10-11 \mu \mathrm{m}$ long is a technically simple and inexpensive method for studying erythrocyte rheology in SCA. Gravity filtration of erythrocytes through $5-\mu \mathrm{m}$ pores is relatively independent of cell size but is sensitive to factors that increase cytoplasmic viscosity, such as an increase in MCHC (15) or in hemoglobin polymerization, making this technique particularly suited to the rheological study of sickle cells. Technical measures used in this study to increase the specificity of the method included removal of contaminating leukocytes, platelets, and plasma proteins so that a pure erythrocyte suspension could be filtered. Test sensitivity was increased by ultrasonic cleaning of the membrane filters so that a small number with similar flow times could be used. We also selected a gravity filtration instrument that generates a relatively low wall shear stress $\left(\sim 56 P_{\mathrm{a}}\right)$ within the membrane pores and operates with a coefficient of variation of $<3 \%(23)$.

Other rheological methods, such as micropipette aspiration, which tests mechanical properties of the erythrocyte membrane (13), and ektacytometry, which monitors cell deformability in a laser diffraction couette viscometer (24), require a greater degree of deoxygenation (sufficient to cause morphological sickling) before they show a rheological change in sickle cells. Erythrocyte filterability through $5-\mu \mathrm{m}$ pores is also more sensitive than viscometry in detecting the reduced deformability of oxygenated (25) or slightly deoxygenated (6) sickle cells. Previous workers have shown a loss of filterability without morphological sickling at high oxygen tension $(6,26)$, but have not attempted to correlate these changes with polymer formation. Our demonstration of the sensitivity of the filtration technique to small differences in polymerization tendency at high oxygen saturation illustrates the potential value of this rheological method for studying the action of antisickling compounds, both in vitro and in clinical trials (27), and for investigating the pathogenesis of vasoocclusion in sickle cell crisis.

In our filtration model, erythrocytes that had been initially deoxygenated for $1 \mathrm{~h}$ consistently showed a higher peak IF (greater loss of filterability) than erythrocytes that had been preequilibrated with atmospheric oxygen for $1 \mathrm{~h}$, for any given $\mathrm{PO}_{2}$. A difference in polymer domain between samples may explain the phenomenon as rapid deoxygenation (occurring in samples subjected to prior deoxygenation for $1 \mathrm{~h}$ ) would be expected to result in the formation of a large number of smaller polymer domains, whereas slow deoxygenation would be expected to give rise to fewer, but large, domains (28). The extent of rheological abnormality may depend on the size, distribution, and number of the domains, even though the total amount of polymer may be identical. Note, however, that despite the increase in the magnitude of IF during the reoxygenation cycle (initially deoxygenated samples) compared with the deoxygenation cycle (samples preequilibrated with atmospheric oxygen), the critical $\mathrm{Po}_{2}$ associated with the abrupt change in IF at high oxygen saturation $(>100 \mathrm{mmHg})$ remains 
almost unchanged (Table I). Unlike the hysteresis sometimes observed in oxygen binding curves for sickle erythrocytes, no such hysteresis behavior was observed in the IF measurements, indicating that the system was close to equilibrium.

This study indicates that sickle erythrocytes may be rheologically abnormal even as they exit from the lungs and that a progressive reduction in oxygen saturation toward venous values will further impair erythrocyte deformability. The $5-\mu \mathrm{m}$ pore filtration technique was originally designed to mimic erythrocyte flow in the microcirculation. The abrupt loss of filtration (Fig. 3) that occurs in the filter pores at a wall shear stress of $\sim 56 P_{\mathrm{a}}$ as polymer increases illustrates the potential for vascular occlusion in vivo at the lower wall shear stresses (estimated maximum $15 P_{\mathrm{a}}$ ) of the microcirculation.

Sickle erythrocytes are not homogeneous, but form a continuous spectrum of cells that can be separated according to density (9). The filtration technique is particularly sensitive to the more dense sickle cells, which after separation on a modified Percoll-Stractan continuous density gradient, were found to lose filterability at a higher oxygen tension than either unfractionated cells or cells of lower density, as previously reported (14). Our pilot study on fractionated cells from four homozygous SCA patients (Table II) gave a calculated polymer fraction at the critical $\mathrm{PO}_{2}$ that was higher for the lighter fraction $2(0.17)$ than for the denser fraction $4(0.11)$. Initialflow-rate filtration through $5-\mu \mathrm{m}$-diam pores is dependent on the cytoplasmic viscosity and MCHC of the filtered cells (15, 29). It is likely that dense sickle cells (fraction 4) in this system lose filterability at a relatively high critical $\mathrm{PO}_{2}$ owing to the combination of their high MCHC (mean of $37.7 \mathrm{~g} / \mathrm{dl}$ for the four patients) and the formation of a small amount of polymer (0.11). Lighter cells (fraction 2) have a lower MCHC (mean of $33.2 \mathrm{~g} / \mathrm{dl}$ ) and therefore required the formation of a larger amount of polymer $(0.17)$ to impair their filterability. The relative contribution of $\mathrm{MCHC}$ and polymer fraction to cytoplasmic viscosity and loss of filterability thus differs between the subpopulations.

In our study of unfractionated sickle cells, the relatively high critical $\mathrm{PO}_{2}$ may have resulted from a disproportionate effect of dense cells, because their preexisting high MCHC and cytoplasmic viscosity would have predisposed them to occlude $5-\mu \mathrm{m}$ pores when only a small amount of polymer had formed. The critical $\mathrm{PO}_{2}$ of unfractionated cells was, however, less than that of dense cells alone, reflecting the presence of lighter cells with a low critical $\mathrm{PO}_{2}$. These lighter cells, while requiring a higher polymer content to impair filterability, may also have made some contribution to the overall correlation $(r=0.844$ 0.881 ) between polymerization tendency and critical $\mathrm{PO}_{2}$ of the unfractionated sample.

The filterability of unfractionated sickle cells was sensitive to oxygen content even at high oxygen saturation and appeared to reflect small changes in polymerization tendency. If these results can be extrapolated to blood flow in vivo, then rheological changes at high oxygen saturation may cause sickle erythrocytes to occlude at the level of precapillary arterioles and sphincters (1).

\section{Acknowledgments}

We thank Dr. Alan Schechter for helpful discussion regarding the manuscript.
We are indebted to the Endowment Fund of the Central Birmingham Health Authority for a research grant, to the Medical Research Council for an intercalated B.Sc. studentship for Dr. Green, and to Action Research For The Crippled Child for financial support to Dr. Keidan.

\section{References}

1. Noguchi, C. T., and A. N. Schechter. 1981. The intracellular polymerization of sickle hemoglobin and its relevance to sickle cell disease. Blood. 58:1057-1068.

2. Noguchi, C. T., and A. N. Schechter. 1985. Sickle hemoglobin polymerization in solution and in cells. Annu. Rev. Biophys. Biophys. Chem. 14:239-263.

3. Glader, B. E., and D. G. Nathan. 1978. Cation permeability alterations during sickling: relationship to cation composition and cellular hydration of irreversibly sickled cells. Blood. 51:983-989.

4. Clark, M. R., J. C. Guatelli, N. Mohandas, and S. B. Shohet. 1980. Influence of red cell water content on the morphology of sickling. Blood. 55:823-830.

5. Bertles, J. F., and J. Döbler. 1969. Reversible and irreversible sickling: a distinction by electron microscopy. Blood. 33:884-898.

6. Chien, S. 1977. Rheology of sickle cells and erythrocyte content. Blood Cells (Berl.). 3:283-303.

7. Sunshine, H. R., J. Hofrichter, F. A. Ferrone, and W. A. Eaton. 1982. Oxygen binding by sickle cell hemoglobin polymers. J. Mol. Biol. 158:251-273.

8. Noguchi, C. T., D. A. Torchia, and A. N. Schechter. 1980. Determination of deoxyhemoglobin $\mathbf{S}$ polymer in sickle erythrocytes upon deoxygenation. Proc. Natl. Acad. Sci. USA. 77:5487-5491.

9. Noguchi, C. T., D. A. Torchia, and A. N. Schechter. 1983. Intracellular polymerization of sickle hemoglobin. Effects of cell heterogeneity. J. Clin. Invest. 72:846-852.

10. Noguchi, C. T. 1984. Polymerization in erythrocytes containing $S$ and non-S hemoglobins. Biophys. J. 45:1153-1158.

11. Brittenham, G. M., A. N. Schechter, and C. T. Noguchi. 1985. Hemoglobin $S$ polymerization: primary determinant of the hemolytic and clinical severity of the sickling syndromes. Blood. 65:183-189.

12. Bessis, M., C. Feo, E. Jones, and M. Nossal. 1983. Adaptation of the Ektacytometer to automated continuous $\mathrm{PO}_{2}$ changes: determination of erythrocyte deformability in sickling disorders. Cytometry. 3:296-299.

13. Nash, G. P., C. S. Johnson, and H. J. Meiselman. 1986. Influence of oxygen tension on the viscoelastic behavior of red blood cells in sickle cell disease. Blood. 67:110-118.

14. Stuart, J., A. J. Keidan, S. S. Marwah, and M. A. Green. 1986. Rheological methods for the evaluation of anti-sickling compounds in clinical trials. In Approaches to the Therapy of Sickle Cell Anaemia. Vol. 141. Y. Beuzard, S. Charache, and F. Galacteros, editors. Les Editions INSERM, Paris. 423-438.

15. Stuart, J., P. C. W. Stone, D. Bareford, and Y. Y. Bilto. 1985. Effect of pore diameter and cell volume on erythrocyte filterability. Clin. Hemorheol. 5:449-461.

16. Stuart, J., P. C. W. Stone, D. Bareford, N. M. Caldwell, J. E. Davies, and S. Baar. 1985. Evaluation of leucocyte removal methods for studies of erythrocyte deformability. Clin. Hemorheol. 5:137-147.

17. Hanss, M. 1983. Erythrocyte filtrability measurement by the initial flow rate method. Biorheology. 20:199-211.

18. Bilto, Y. Y., and J. Stuart. 1985. Ultrasonic cleaning of polycarbonate membranes for measurement of erythrocyte filterability. Clin. Hemorheol. 5:437-448.

19. Molden, D. P., N. M. Alexander, and W. E. Neeley. 1982. Fetal hemoglobin: optimum conditions for its estimation by alkali denaturation. Am. J. Clin. Pathol. 77:568-572.

20. Bessis, M. 1972. Red cell shapes. An illustrated classification and its rationale. Nouv. Rev. Fr. Hematol. 12:721-746.

21. Fabry, M. E., and R. L. Nagel. 1982. Heterogeneity of red cells 
in the sickler: a characteristic with practical clinical and pathophysiological implications. Blood Cells (Berl.). 8:9-15.

22. Martin-Caburi, J., T. Hermann, M. C. Garel, C. Domenget, F. Galacteros, J-C. Healy, M. Hanss, and Y. Beuzard. 1982. Utilisation d'un nouveau rhéomètre pour étudier la filtrabilité d'une suspension de globules rouges drepanocytaires en fonction de la $\mathbf{P O}_{2}$. Compt. Rend. Acad. Sci. Paris. 295:355-358.

23. Bareford, D., P. C. W. Stone, N. M. Caldwell, H. J. Meiselman, and J. Stuart. 1985. Comparison of instruments for measurement of erythrocyte deformability. Clin. Hemorheol. 5:311-322.

24. Sorette, M. P., M. G. Lavenant, and M. R. Clark. 1987. Ektacytometric measurement of sickle cell deformability as a continuous function of oxygen tension. Blood. 69:316-323.

25. Stäubli, M., P. C. W. Stone, P. W. Straub, and J. Stuart. 1986.
Evaluation of methods for measuring erythrocyte deformability. Clin. Hemorheol. 6:589-602.

26. Ohnishi, S. T. 1982. Viscosity and filtrability measurements of sickle-cell suspensions in the development of anti-sickling drugs. Blood Cells 8:79-87.

27. Keidan, A. J., I. M. Franklin, R. D. White, M. Joy, E. R. Huehns, and J. Stuart. 1986. Effect of BW12C on oxygen affinity of haemoglobin in sickle-cell disease. Lancet. i:831-834.

28. Ferrone, F. A., J. Hofrichter, and W. A. Eaton. 1985. Kinetics of sickle hemoglobin polymerization. I. Studies using temperaturejump and laser photolysis techniques. J. Mol. Biol. 183:591-610.

29. Reinhart, W. H., and S. Chien. 1985. Roles of cell geometry and cellular viscosity in red cell passage through narrow pores. Am. J. Physiol. 248:C473-C479. 